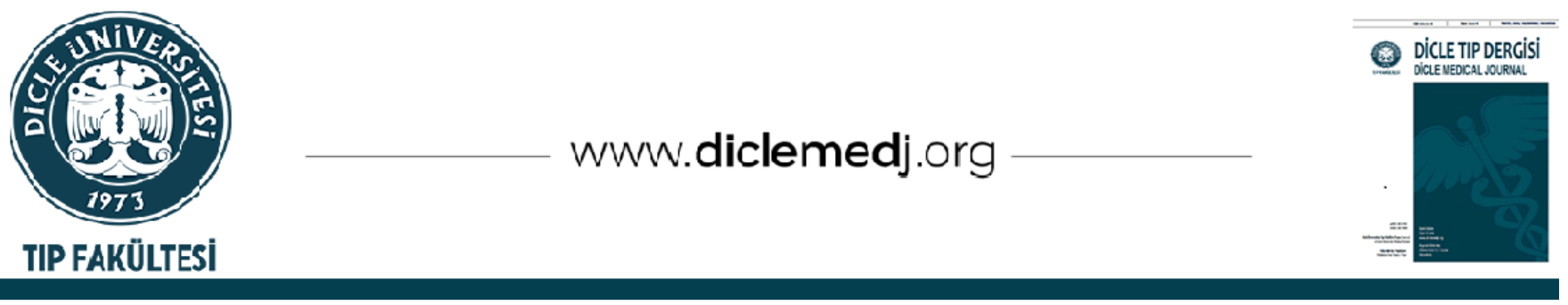

\title{
Çeşitli Klinik Örneklerden İzole Edilen Stenotrophomonas maltophilia Suşlarının Dağılımı ve Antimikrobiyal Duyarlılıkları: 8 Yılık Çalışma
}

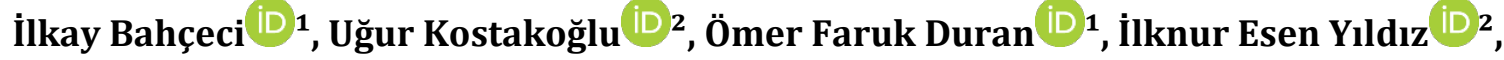 \\ Aziz Ramazan Dilek iD 1
}

1 Recep Tayyip Erdoğan Üniversitesi Tıbbi Mikrobiyoloji Anabilim Dalı/Rize, Türkiye

2 Recep Tayyip Erdoğan Üniversitesi Enfeksiyon Hastalıkları Anabilim Dalı/Rize, Türkiye

Geliş: 31.01.2020; Revizyon: 13.01.2021; Kabul Tarihi: 18.01.2021

Öz

Amaç: Hastane enfeksiyonları ve buna bağlı mortalitenin artması çoklu ilaç direncine sahip firsatçı patojenleri her zamankinden daha fazla gündeme getirmiştir. Bunlar arasında yer alan stenotrophomonas maltophilia önemi giderek artan fırsatçı bir patojendir. Bu çalışmanın amacı,sekiz yıllık süre boyunca hastanemizde çeşitli klinik örneklerden izole edilmiş S. maltophilia izolatlarının dağılımını ve antimikrobiyal duyarlılıklarını araștırmaktır.

Yöntemler: Ocak 2011-Aralık 2019 tarihleri arasında çeşitli klinik örneklerden izole edilen toplam 149 S. maltophilia suşunun antimikrobiyallere direnç oranları araştırıldı. Bakteri identifikasyonu ve antibiyotik duyarlılığı rutin konvansiyonel mikrobiyolojik yöntemler ve VITTEK 2 kompakt otomatize sistem (BioMerieux, France) ile yapılmıştır.

Bulgular: S. maltophilia en sık yoğun bakım ünitelerinde izole edilirken $50(\% 33,5)$, en az 1 örnekle $(\% 0,6)$ Kardiyovasküler cerrahi servisi, Pediatri servisinden izolasyon gerçekleşmiștir. Örneklerin 85 ’i (\%57,) solunum yolu izolatları olurken (trakeal aspirat, lavaj, balgam), en az 1 örnek ( \%0,6) ile plevra ve eklem sivisı olmuştur. Karbapenemlere doğal direnç gösteren S. maltophilia'da levofloksasin direnci \% 6 iken, trimetoprim/sulfametoksazol'de $\% 12$, seftazidim'de $\% 45$ olarak tespit edilmiştir.

Tartışma ve Sonuç: Çalışmada saptanan yüksek direnç oranları nedeniyle, S. maltophilia suşlarının etken olduğu nozokomiyal enfeksiyonların tedavisinde mümkün olduğunca in vitro duyarlılık testlerinin yapılması gerekir. Bunun yapılamadığı durumlarda ise tedavi planlamasında trimetoprim-sulfametoksazol ve levofloksasin iyi birer tedavi seçeneğidir. Ayrıca tedaviye başlamadan önce kolonizasyon - etken ayrımı klinik bulgularda göz önünde tutularak birlikte karar verilmelidir.

Anahtar kelimeler: Antimikrobiyal duyarlılık, direnç, stenotrophomonas maltophilia

DOI: 10.5798/dicletip.887633

Correspondence / Yazışma Adresi: İlkay Bahçeci, Recep Tayyip Erdoğan Üniversitesi Tıbbi Mikrobiyoloji Anabilim Dalı/Rize, Türkiye e-mail: bahceciie@hotmail.com 


\title{
Distribution and Antimicrobial Susceptibilities of Stenotrophomonas maltophilia Strains Isolated from Various Clinical Samples: An 8-Year Study
}

\begin{abstract}
Objective: Hospital infections which associated with increased mortality have brought opportunistic pathogens like Stenotrophomonas maltophilia, with multiple drug resistance into focus. The aim of this study was to investigate the distribution and antimicrobial susceptibility of S. maltophilia isolates obtained from various clinical samples in our hospital for a period of eight years.

Method: Antimicrobial resistance rates of 149 strains of S. maltophilia isolated from various clinical samples between January 2011 and December2019 were investigated. Bacterial identification and antibiotic susceptibility were performed with routine conventional microbiological methods and the VITEK 2 compact automated system (BioMerieux, France).

Results: While S. maltophilia was most frequently isolated in intensive care units, from a total of 50 samples (33.5\%), the rate was $0.6 \%$ ( 1 sample) the cardio vascular surgery service and pediatrics services. 85 (57\%) of the samples were respiratory tract isolates (tracheal aspirate, lavage, sputum) with at least $1(0.6 \%)$ pleural and joint fluid. Among these isolates of S maltophilia, which shows natural resistance to carbapenems, resistance for levofloxacin was $6 \%$ and for trimethoprim/ sulfamethoxazole was $12 \%$.

Conclusion: Due to the high resistance rates observed in the study, in vitro susceptibility tests should be used as much as possible in the treatment of nosocomial infections caused by S. maltophilia strains. In cases where this is not possible and empirical treatment is required, trimethoprim-sulfamethoxazole and levofloxacin are reasonable treatment options. Also, before starting treatment, the separation between colonization and agent should be decided in accordance with the clinical findings.
\end{abstract}

Keywords: Antimicrobial susceptibility, resistance, stenotrophomonas maltophilia.

\section{GíRiş}

Stenotrophomonas maltophilia daha önce Xanthomonas maltophilia veya Pseudomonas maltophilia olarak bilinen çoklu ilaca dirençli, aerobik, nonfermantatif, oksidaz negatif, hareketli, gram negatif basildir ${ }^{1,2}$. S. maltophilia giderek artan oranda hastane kökenli enfeksiyonlara neden olan patojen olarak tanımlanmaktadır ${ }^{1}$. Penisilinlere, üçüncü kuşak sefalosporinlere, aminoglikozidlere ve karbapenemlere direncinden dolayı yoğun bakım ünitelerinde önemli bir problem olmaktadır ${ }^{3-6}$. Hastanede kalış süresinin ve yoğun bakım ünitelerinde yatış ihtiyacının yüksek oranlara gelmesi, kronik solunum yolu hastalıkları, geniş spektrumlu antibiyotik kullanımının artması, malignensiler, immünsupresyon, koruyucu bariyerin bozulması gibi risk faktörleri olanlarda S. maltophilia, enfeksiyonu görülme olasılığı artar6,7.

$\mathrm{Bu}$ çalışma ile hastanemizde izole edilen $\mathrm{S}$. maltophilia izolatlarının hangi klinik örneklerden izole edildiğini, izole edilen örneklerin kliniklere göre dağılımı ve direnç durumlarını saptayarak daha sonra yapılacak ilgili çalışmalarda direnç oranlarının karşılaştırılabilmesine imkan sağlamak, epidemiyolojik verilere katkı sunmak amacı ile yapılmıștır.

\section{YÖNTEMLER}

Recep Tayyip Erdoğan Üniversitesi (RTEÜ) Tıp Fakültesi Eğitim ve Araştırma Hastanesi rutin mikrobiyoloji laboratuvarına Ocak 2011-Aralık 2019 tarihleri arasında gönderilen ve çeşitli klinik örneklerde üreyen S. maltophilia izolatları retrospektif olarak incelenmiştir. Tekrarlayan örnekler çalışmaya dahil edilmemiştir. Klinik örnekler \%5 koyun kanlı agar, eozin metilen blue agar ve çikolatamsı agar besiyerlerine, sayım ve seyreltme yöntemi ile ekilmiştir. Ekim yapılan besiyerleri $36 \pm 1^{\circ} \mathrm{C}^{\prime}$ lik ısı değerinde etüvde aerobik olarak 24-48 saat süresince inkübe edilmiștir. Gram boyama değerlendirme neticesinde gram negatif basil görünümünde olan, katalaz testi pozitif, oksidaz testi negatif, nonfermentatif, hareketli bakteriler konvansiyonel mikrobiyolojik yöntemler ve VITEK 2 kompakt otomatize sistem (BioMerieux, 
France) ile identifiye edilmiş ve antimikrobiyal duyarlılığı çalışılmıştır. Antimikrobiyal duyarlılığının tespit edilmesinde 2011-2016 yılları arasında Clinical Laboratory Standards Institute (CLSI)- 2011 ve (CLSI) tarafından S. maltophilia izolatları için tavsiye edilen A grubu antimikrobiyal olarak trimetoprim-sulfametoksazol (TMPSXT), B grubu antimikrobiyal olarak da levofloksasin ve seftazidim alınmış iken 2017-2019 tarihleri arasında izole edilen suşlarda European Committee on Antimicrobial Susceptibility Testing (EUCAST) 2017 referans olarak kabul edilmiş ve yine aynı şekilde önerilen A grubu antimikrobiyal olarak (TMPSXT), B grubu antimikrobiyal olarak da levofloksasin ve seftazidim alınmıştır.

Çalışmada örnek sayısı n olarak gösterildi ve yüzde olarak hesaplandı. Çalışmanın istatiksel analizinde SPSS (Statistical Packages of Social Sciences,SPSS for Windows, Version 21.0, Chicago, IC, USA) paket programı kullanıldı. 40465587-155 nolu sayı ile RTEÜ Girişimsel Olmayan Klinik Araştırmalar Etik Kurul onayı alınmıştır.

\section{BULGULAR}

Toplam 149 örnek çalışmaya dahil edildi. Örneklerin 90(\%60,4)'ı erkek hastalardan, 59 (\%39,6)'u kadın hastalardan izole edildi. Demografik verilere bakıldığında yaş ortalaması $68 \pm 3,6$ yıl olarak bulundu. S. maltophilia izolatlarının $85(\% 57)$ 'si en slk solunum yolu örneklerinden, 1 ile $(\% 0,6)$ en az plevra ve eklem sıvısı örneklerinden üretilmişlerdir. Bu suşların $50(\% 33,6)$ 'si yoğun bakımda yatan, 49 $(\% 32,8)$ servislerde yatan ve $14 \quad(\% 9,4)$ 'ü poliklinikte yatışları olmayan hastalardan izole edilmiştir. Gögüs Hastalıkları Servisi izolatları içinde Gögüs Hastalıklarına bağlı birinci basamak yoğun bakım izolatları da dahil olduğu için ayrı bir bölüm olarak değerlendirilmiş olup, izolat sayısı da $36(\% 24,1)$ dır. Suşların izolasyon oranlarına binaen sırasıyla olmak üzere en sık solunum yolu örnekleri $(\mathrm{n}=85)$, devaminda idrar $(\mathrm{n}=26)$, kan örnekleri $(n=10)$, yara örnekleri $(n=9)$, doku örnekleri $(n=8)$ ve en az kateter örnekleri $(\mathrm{n}=5)$ izlemiştir (Tablo I).

Tablo I: S. maltophilia suşlarının izole edildikleri klinik ve örneklere göre dağılımı

\begin{tabular}{|c|c|c|c|c|c|c|c|c|c|c|c|c|c|c|c|c|c|c|c|c|}
\hline Örnek & Ay & Dy & Cy & Ky & Py & Gs. & Ts & Ds & Hs & Ge & Ks & Ns & Kv & Us & Çs & Fs & Os & Es & $\mathbf{P}$ & $\mathbf{T}$ \\
\hline TAK & 8 & 9 & 9 & 3 & 4 & 4 & & & & & & & 1 & & & & & & & 38 \\
\hline Balgam & 1 & & & & 3 & 12 & & & 2 & 1 & 2 & & & & 1 & & & & 5 & 27 \\
\hline Lavaj & 1 & & 1 & & & 18 & & & & & & & & & & & & & & 20 \\
\hline Kan & 1 & & 2 & & 1 & & & & & & 1 & 1 & & & & 1 & & 2 & 1 & 10 \\
\hline Yara & & & & & & & 1 & 2 & 1 & & & 2 & & & & & 1 & & 2 & 9 \\
\hline İdrar & & & & & 2 & 2 & 1 & 8 & 2 & & & 2 & & 3 & & 2 & & 2 & 2 & 26 \\
\hline Kateter & & & 1 & & & & 1 & & & & & 1 & & & & & & 1 & 1 & 5 \\
\hline Assit & & 1 & & & & & & & & 1 & & & & & & & & & & 2 \\
\hline $\begin{array}{l}\text { Kulak } \\
\text { akıntısı }\end{array}$ & & & & & & & & & & & & & & & & & & & 2 & 2 \\
\hline $\begin{array}{l}\text { Eklem } \\
\text { Sivısı }\end{array}$ & & & & & & & & & & & & & & & & & & & 1 & 1 \\
\hline Plevra & & & 1 & & & & & & & & & & & & & & & & & 1 \\
\hline Doku & & 2 & & & & & & 1 & & & & & & & & & 5 & & & 8 \\
\hline Toplam & 11 & 12 & 14 & 3 & 10 & 36 & 3 & 11 & 5 & 2 & 3 & 6 & 1 & 3 & 2 & 1 & 6 & 5 & 14 & 149 \\
\hline
\end{tabular}

Ay: Anestezi Yoğun Bakım Servisi, Dy: Dahiliye Yoğun Bakım Servisi,Cy: Cerrahi Yoğun Bakım Servisi,Ky: Koroner Yoğun Bakım Servisi, Py: Palyatif Yoğun Bakım Servisi ,Gs: Göğüs Hastalıkları Servisi, Ts: Tıbbi Onkoloji Servisi, Ds: Dahiliye Servisi, Hs: Hematoloji Servisi, Ge: Gastroenteroloji Servisi,Ks: Kardiyoloji Servisi, Ns: Nefroloji Servisi, Kv: Kardiyovasküler Cerrahi Servisi, Üs: Üroloji Servisi, Çs: Çocuk Hastalıkları Servisi, Fs: Fizik Tedavi ve Rehabilitasyon Servisi, Os :Ortopedi ve Travmatoloji Servisi, Es: Enfeksiyon Servisi, P: Çeşitli Poliklinikler, T: Toplam 
S.maltophilia izolatların antimikrobiyal duyarlılık testi sonuçları gözden geçirildiğinde, en yüksek duyarlılığa sahip antimikrobiyal \%94 ile levofloksasin olurken takiben \%88 ile TMPSXT \%55 ile seftazidim olarak tespit edilmiştir(Tablo II).

Tablo II: S. maltophilia suşlarının antimikrobiyal duyarlılıkları

\begin{tabular}{|l|l|}
\hline Antibiyotik & $\begin{array}{l}\text { Duyarlı suş sayısı n } \\
(\%)\end{array}$ \\
\hline $\begin{array}{l}\text { Trimetoprim- } \\
\text { Sulfametaksazol(TMP-SXT) }\end{array}$ & $131(88)$ \\
\hline Levofloksasin & $140(94)$ \\
\hline Seftazidim & $78(55)$ \\
\hline
\end{tabular}

\section{TARTIŞMA}

S. maltophilia, nonfermantatif bir bakteri olarak doğada, toprakta sularda bitkilerde kaynak suları gibi pek çok ortamda bulunabilen bir etkendir6. Nazokomiyal morbidite ve mortaliteyi artırmasının yanı sıra toplum kaynaklı enfeksiyonlara da yol açmaktadır?. Çalışmamızda izolatların yaklaşık $50(\% 33,6)$ ü en sık yoğun bakım ünitelerinden izole edilmiștir. Gallo ve ark. ile Esposito ve ark.'ının gerçekleştirdiği çalışmada S. maltophilia'nın en sık yoğun bakım ünitelerinden izole edilmiştir8,9. Ülkemizde ise Kandemir ve ark.' 1 nın çalışmasında da \%70 ile en sık örneklerin geldiği yer yoğun bakım üniteleri idi ${ }^{10}$. S. maltophilia'nın en sık yoğun bakım üniteleri enfeksiyonların da izole edilmesinin arkasında hastanede ve özellikle yoğun bakım da uzun süreli yatış, mekanik ventilasyon, girişimsel işlemler, geniş spektrumlu antibiyotik kullanma, immun sistemdeki baskılanma ve zayıflama gibi risk faktörleri yer almaktadır ${ }^{11,12}$. S. maltophilia sağlıklı kişiler yerine immun sistemi baskılanmış kişilerde enfeksiyon etkenidir. Bundan dolayıdır ki S. maltophilia'nın yol açtığı solunum yolu enfeksiyonlarının prognozu kötü olmaktadır ${ }^{13}$. Kandemir ve ark,'ının yaptığı çalışmada S. maltophilia en sık \%40 ile kan örneklerinden izole edilirken bizim çalışmamızda \%57 ile en sık solunum yolu örneklerinden izole edilmiştir ${ }^{10}$. Avcl ve ark.'ının yaptığı çalışmada genel yaş ortalaması 53 yıl, kadınlarda görülme sıklığı \%31 iken bizim çalışmamızda yaş ortalaması $68 \pm 3,6$ yıl, kadınlarda görülme sıklığı \%39,6 olmuştur ${ }^{14}$. Ortalama ömrün uzamış olması bunda bir faktör olabilir. Literatürdeki veriler daha çok erişkin grubuna ait olsa da, yenidoğan ve pediatrik yaş gruplarında S. maltophilia görülme sıklığı artan nazokomiyal etkenler arasındadır. Kandemir ve ark.'ının yaptığı çalışmada örneklerin \%38'i çocuk yaş grubuna aitti10.

Tüm dünyanın katılım gösterdiği 1997 Ocak ile 2003 Aralık tarihlerinde yapılan SENTRY Antimikrobiyal Sürveyans Program çalışması sonuçlarına göre, 2076 S. maltophilia suşunda antimikrobiyal duyarlılı gözden geçirildiğinde, TMPSXT'e \%95,3, levofloksasine \%93,5, gatifloksasine $\% 85,9$, siprofloksasine $\% 63,1$, polimiksin B'ye \%67,6, tikarsilin-klavulanik aside $\% 55,7$ ve seftazidime $\% 52,9$ oranında duyarlılık saptanmıştır ${ }^{15}$. Ayrıca S. maltophilia'nın yaklaşık \%29,9'u tedavisinde ilk kullanılması gereken ilacın TMP-SXT olduğu bildirilse de, bu moleküle karşı da direnç geliştiği yönünde çalışmalar giderek artan oranda bildirilmektedir ${ }^{16,17}$. Bu çalıșmada ise karbapenemlere doğal direnç gösteren S. maltophilia'da TMPSXT duyarlılığı \%88 olarak tespit edilmiştir. Bizim çalışmamızla benzerlik gösteren, Kandemir ve arkadaşlarının yaptığı çalışmada da S. Maltophilia izolatlarının \%90,5'inin SXT'ye duyarlı olduğu görülmüştür ${ }^{10}$. Yapılan başka bir çalışmada ise Tekin ve ark. SXT duyarlılığı \%57 olarak tespit etmişlerdir ${ }^{18}$. Guerci ve ark.'ının 2019 Fransa'da yaptıkları çok merkezli bir çalışmada bizim 
çalışmamıza benzer şekilde TMP-SXT duyarlılığını \%88 civarında bulmuşlardır ${ }^{19}$.

Kinolonlar da S. maltophilia enfeksiyonlarında TMP-SXT kadar sonuç alınan diğer moleküllerdir. Son nesil kinolon moleküllerinin tedavide daha etkili olduğu yönünde raporlar bildirilmiştir. Trovafloksasin, klinafloksasin, gatifloksasin, moksifloksasin, grepafloksasin ve levofloksasinin siprofloksasinden 4-8 kat daha etkili oldukları bildirilmiştir ${ }^{20}$. Kandemir ve ark.'nın yaptığı çalışmada, yurt içi çalışmalarla benzer şekilde levofloksazin duyarlılı̆g $\% 78$ saptanırken ${ }^{10}$, Türkdağı ve ark.'nın yaptığı çalışmada $\% 80$ olarak bulunmuştur ${ }^{21}$. Tekin ve ark.'nın yaptığı çalışmada ise \%75 tespit edilmiștir ${ }^{18}$. Bizim yaptığımız çalışmada ise $\mathrm{S}$. maltophilia'da levofloksasin duyarlılığı \%94 olarak saptanmıştır. Bu sonuç hastanemizdeki direnç profili açısından umut vaat etmektedir. Dünyada ise İtalya'da yapılan bir çalışmada levofloksazin duyarlılığı yaklaşık \%72 olarak saptanmıștır ${ }^{22}$. Yine yurtdışında yapılan birçok merkezin olduğu başka bir çalışmada, levofloksasin duyarlılı oranları Kuzey Amerika'da \%91,6, Avrupa'da \%91,5, Latin Amerika'da \%96,2, Asya-Pasifik'de \%88,3 bulunmuştur ${ }^{23}$. Tayvan'da gerçekleştirilen diğer bir çalışmada ise $\% 20,4$ olarak bildirilmiștir ${ }^{24}$.

Ulusal çalışmalarda seftazidim direncini Dizbay ve ark. ${ }^{25} \% 45$, Kandemir ve ark. \%77 olarak bildirmişlerdir ${ }^{10}$. Uluslararası çalışmalarda ise Hsueh ve ark. Tayvan'da \%85, İsmail ve ark. Malezya'da \%74, Farrell ve ark. ise Amerika'nın kuzeyinde \%34,9, Asya-Pasifik'de ise \%53,5 olarak saptamışlardır $23,26,27$. Bizim çalışmamızda ise seftazidim direnci \%47 olarak belirlenmiștir.

Sonuçta, artan direnç oranları nedeniyle, S. maltophilia suşlarının etken olarak tanımlandığı nozokomiyal enfeksiyonların tedavisinde mümküm olduğu ölçüde invitro duyarlılık testlerinin yapılması gerekir. Eğer bu testleri yapmak mümkün değilse ve tedavi planlaması yapılıyor ise TMPSXT ve levofloksasin ampirik tedavide iyi bir tercih olacaktır. Ayrıca tedaviye başlamadan önce kolonizasyon - etken ayrımı klinik bulgularda göz önünde tutularak karar verilmelidir. Ek olarak değişen direnç oranlarını sürekli takip ederek her merkezin kendi antimikrobiyal duyarllık verilerini güncelleyip son verilere sahip olmanın önemli olduğunu bilinmelidir.

Etik Kurul Kararı: 40465587-155 nolu sayı ile RTEÜ Girişimsel Olmayan Klinik Araştırmalar Etik Kurul onayı alınmıştır.

Çıkar Çatışması Beyanı: Yazarlar arasında çıkar çatışması yoktur.

Finansal destek: Çalışma için finansal destek alınmamıştır.

Declaration of Conflicting Interests: The authors declare that they have no conflict of interest.

Financial Disclosure: No financial support was received.

\section{KAYNAKLAR}

1. Pien C, Kuo H, Chang S, et al. Risk factors for levofloxacin resistance in Stenotrophomonas maltophilia from respiratory tract in a regional hospital. J Microbiol Immunol Infect 2015; 48: 291-5.

2. LevinsonW, Rewiew of Medical Microbiology and Immunology McGraw-Hill14rd. Edn California 2018; 18: 165,661 .

3. Guyot A, Turton J, Garner D. Outbreak of Stenotrophomonas maltophilia on an intensive care unit. J HospInfect 2013; 85: 303-7.

4. Garazi M, Singer C, Tai J, et al. Blood stream infections caused by Stenotrophomonas maltophilia: a sevenyear review. J HospInfect 2012; 81: 114-8.

5. Wood G, Underwood E, Croce M, et al. Treatment of recurrent Stenotrophomonas maltophilia ventilatorassociated pneumonia with doxycycline and aerosolized colistin. Ann Pharmac other 2010; 44: 1665-8.

6. Saugel B, Eschermann K, Hoffmann R, et al. Stenotrophomonas maltophilia in the respiratory tract of medial intensive care unit patients. Eur J Clin Microbiol Infect Dis 2012; 31: 1419-28.

7. Brooke J.Stenotrophomonas emerging global opportunistic pathogen. Clin Microbiol Rev 2012;25:2-41. 
8. Gallo SW, Ramos PL, Ferreira CAS, et al. A specific polymerase chain reaction method to identify Stenotrophomonas maltophilia. MemInst Oswaldo Cruz. 2013; 108: 390-1.

9. Esposito A, Pompilio A, Bettua C, et al. Evolution of Stenotrophomonas maltophilia in cystic fibrosis lung over chronic infection: a genomic and phenotypic population study. Front Microbiol. 2017; 8: 1590.

10. Kandemir I, Özcan N, Alanbayı Ü, ve ark. Klinik Örneklerden İzole Edilen Stenotrophomonas maltophilia Suşlarının Dağılımı ve Antimikrobiyal Duyarlılıkları, Dicle Medical Journal 2016; 43: 237-40.

11. Nseir S, DiPompeo C, Brisson $\mathrm{H}$, et al. Intensive care unit-acquired Stenotrophomonas maltophilia: incidence, risk factors, and outcome. CritCare. 2006; 10: R143.

12. Metan G, Hayran M, Hascelik G, Uzun O. Which patient is a candidate for empirical therapy against Stenotrophomonas maltophilia bacteraemia? An analysis of associated risk factors in a tertiary care hospital. Scand J InfectDis. 2006; 38: 527-31.

13. Hanes SD, Demirkan K, Tolley E, et al. Risk factors for late-onset nasocomial pneumonia caused by Stenotrophomonas maltophilia in criticallyill trauma patients. ClinInfectDis. 2002; 35: 228-35.

14. Avcı M, Özgenç 0 , Coşkuner SA, et al. Hastane Kökenli Stenotrophomonas maltophilia İnfeksiyonlarının Değerlendirilmesi. FLORA 2010; 15: 153-9.

15. Sader HS, Jones RN. Antimicrobial susceptibility of uncommonly isolated non-enteric gram-negative bacilli. Int J Antimicrob Agents 2005; 25: 95-109.

16. Toleman MA, Bennett PM, Bennett DM, et al. Global emergence of trimethoprim/sulfamethoxazole resistance in Stenotrophomonas maltophilia mediated by acquisition of sulgenes. Emerg Infect Dis2007; 13: 559-65.

17. Fedler KA, Biedenbach DJ, Jones RN. Assessment of pathogen frequency and resistance patterns among pediatric patient isolates: report from the 2004 SENTRY Antimicrobial Surveillance Program on 3 continents. Diagn Microbiol Infect Dis 2006; 56: 42743.

18. Tekin A, Dal T, Tekin R, et al. Klinik Örneklerden İzole Edilen Stenotrophomonas maltophilia Suşlarının İn Vitro Antibiyotik Duyarlılık Paterni. Düzce Tıp Fakültesi Dergisi 2014; 16: 4.
19. Guerci P, Bellut H, Mokhtari M, et al. Outcomes of Stenotrophomonas maltophilia hospital-acquired pneumonia in intensive care unit: a nation wide retrospective study.Critical Care 2019 23:371 https://doi.org/10.1186/s13054-019-2649-5

20. Valdezate S, Vindel A, Loza E, et al. Antimicrobial susceptibilities of unique Stenotrophomonas maltophilia clinical strains. Antimicrob Agents Chemother 2001; 45: 1581-4.

21. Türk Dağı H, Arslan U, Tuncer İ. Kan kültürlerinden izole edilen Stenotrophomonas maltophilias uşlarının antibiyotik direnci. Ankem Dergisi 2011; 25: 27-30.

22. Pompilio A, Savini V, et al. Clonal Diversity, Biofilm Formation, and Antimicrobial Resistance among Stenotrophomonas maltophilia Strains from Cystic Fibrosis and Non-Cystic Fibrosis Patients. Antibiotics (Basel). 2020 Jan 2; 9. pii: E15. doi: 10.3390/ antibiotics 9010015

23. Farrell DJ, Sader HS, Jones RN. Antimicrobial susceptibility of a world wide collection of Stenotrophomonas maltophilia isolates tested against tigecycline and agents commonly used for S. maltophilia infections. Antimicrob Agents Chemother 2010; 54: 2735-7.

24. Wu H, Wang JT, Shiau YR, et al. A multi center surveillance of antimicrobial resistance on Stenotrophomonas maltophilia in Taiwan. J Microbiol Immunol Infect 2012; 45: 120126.

25. Dizbay M, Tunçcan ÖG, Maral I, et al. Five year surveillance of nosocomial Stenotrophomonas maltophilia infections in Gazi University Hospital. Turkiye Klinikleri J MedSci 2009; 29: 1406-11.

26. Hsueh S.C, Lee Y, Huang Y.T et al. Invitro activities of cefiderocol, ceftolozane/tazobactam, ceftazidime/ avibactamandother comparative drugs against imipenem-resistant Pseudomonas aeruginosa and Acinetobacter baumannii, and Stenotrophomonas maltophilia, all associated with blood stream infections in Taiwan Antimicrob Chemother 2019; 74: 380-6.

27. Ismail N, Zam Z, Hassan S. A, et al. A Combination of Trimethoprim-sulfamethoxazole and Ceftazidime Showed Good InVitro Activity against Stenotrophomonas maltophilia Malays J Med Sci. MarApr 2017; 24: 21-7. 